\title{
MOLTEN SALT FLOW AND HEAT TRANSFER IN PADDLE HEAT EXCHANGERS
}

\author{
Kai Zhang, Jiangyong Du, Xinzhi Liu and Houlei Zhang* \\ Nanjing University of Science and Technology, Xiaolingwei 200, Nanjing 210094, P. R. China \\ Email: houlei_zhang@aliyun.com
}

\begin{abstract}
Constructal law has inspired a large amount of work in fluid flow and heat transfer analysis, design and optimization. In this paper the authors will investigate high temperature $\left(\sim 500^{\circ} \mathrm{C}\right)$ molten salt flow and heat transfer characteristics in paddle heat exchangers (more general name of paddle dryers) by invoking constructal law idea and CFD tools. The research shows that among three typical paddle-shaft structures, open hollow paddle-shaft structure transfers more heat than solid paddleshaft structure and closed hollow paddle-shaft structure for specified inclined angle of paddles and inlet flow rate. The performance superiority of open hollow paddle-shaft structure demonstrates the design optimization direction or constructal evolving direction. Next, under the constraint of the outside surface shape which is determined by the flow of outside materials, the effects of the open hole position, size, non-finned angle, as well as the pressure drop (in dimensionless form, Bejan number) on flow and heat transfer for open hollow paddles are calculated. There exists an open hole position at which pressure drop and heat transfer rate approach maximum simultaneously for specified flow rates. The flow rate and heat transfer rate increase significantly as the hole diameter increases. When the non-finned angle decreases, the heat transfer rate increases whereas the change of the flow rate is not monotonous. Finally, the comparison of original and modified rotary joints shows that internal heat insulation combined with external cooling reduces the average temperature in the sealing packing domain greatly which helps improve the sealing performance under high molten salt temperature conditions. The present work provides more insight in molten salt flow and heat transfer in paddle heat exchangers and provides reference data for design engineers.
\end{abstract}

Keywords: Constructal law, Paddle heat exchanger, Paddle-shaft, Rotary joint, Design.

\section{INTRODUCTION}

Paddle dryer is one kind of indirect dryer that has been used in removing moisture of many materials [1], such as sewage sludge [2-7], brown coal [8], coal slime [9] etc. In drying processes, steam or heat transfer oil is the normal working fluids in the temperature range less than $300^{\circ} \mathrm{C}$. In order to extend the temperature range up to $600^{\circ} \mathrm{C}$, molten salts (e.g., Hitec salt) become favorable candidates. Paddle dryer is then given a more general name - paddle heat exchanger as its application is beyond the scope of drying. Although molten salt flow and heat transfer in simple ducts and some applications (e.g., solar thermal power systems) have been investigated extensively [10-20], no research on molten salt paddle heat exchangers is presented.

In this paper we will study molten salt paddle heat exchangers by invoking constructal law-based methodology constructal design method (CDM) [21]. In many instances, heat transfer rate is the design objective with specified constraints (e.g., volume, work consumption and mechanical strength etc.). Optimization or trade-off is critical. CDM provides a view for designing and optimizing thermofluid systems via evolving their flow architecture [22-30], such as from uniform structures to multi-scale structures. For molten salt paddle heat exchangers, salt flows in hollow shaft and granular or pasty materials flow on the shell-side (i.e. outside).
If the convective heat transfer coefficients on the two sides are in the same scale which is valid in some cases, molten salt-side heat transfer optimization is important. In this paper, we will present molten salt flow and heat transfer performance in paddle-shaft structures and in rotary joints.

\section{MODEL}

Consider a $3 \mathrm{~m}^{2}$ (nominal heat transfer area) and two-shaft type paddle heat exchanger with Hitec salt $\left(53 \% \mathrm{KNO}_{3}-40 \%\right.$ $\mathrm{NaNO}_{2}-7 \% \mathrm{NaNO}_{3}$ ) as the heat transfer fluid (Fig.1). In general, the working temperature of Hitec salt is less than $535^{\circ} \mathrm{C}$ [31]. The number of pairs of paddles is $N(=23$ in this paper), and the inclined angle of paddles is $\alpha$. The shell-side material is driven by rotating paddles, and heated by hot molten salt via paddle-shaft surfaces. Select one element (with one pair of paddles) for analysis (Fig.2). The outside surface shape of the paddle determined by shell-side flow design is specified as the constraint of molten salt-side design.

Figure 3 shows three types of paddles, solid paddle, closed hollow paddle and open hollow paddle. For closed hollow paddles, natural convection of air occurs in closed cavities (Fig. 3b), and for open hollow paddles, forced convection of molten salt happens in the inner space (duct) of paddles (Fig. $3 \mathrm{c})$. The first work in this paper is to compare the three 
paddle-shaft structures (Section 3). To further investigate the relationship between the structure and performance of open hollow paddles (Section 4), we selected the computational domain shown in Fig. 4.

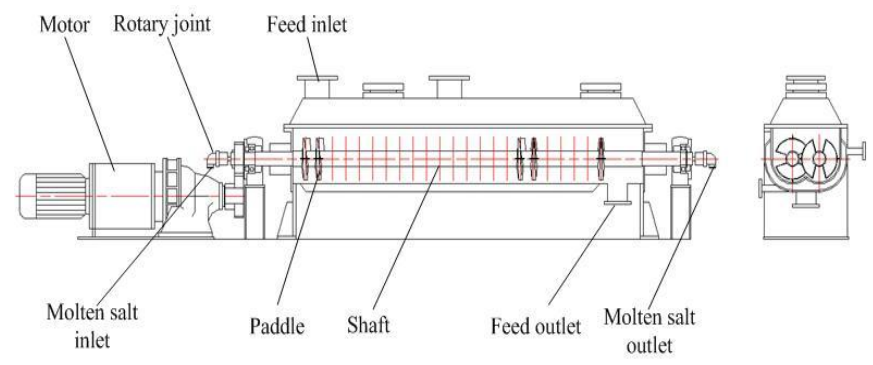

Figure 1. Scheme of two-shaft paddle heat exchanger

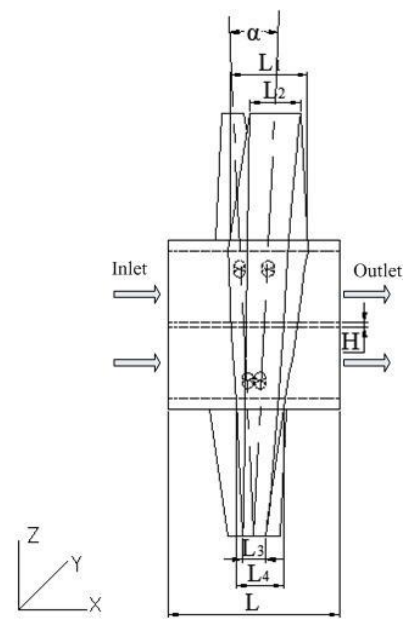

Figure 2. Computational element of paddle-shaft structure $\left(\alpha=3^{\circ}, L_{1}=28 \mathrm{~mm}, L_{2}=18 \mathrm{~mm}, L_{3}=8 \mathrm{~mm}, L_{4}=17 \mathrm{~mm}\right.$, $H=2 \mathrm{~mm}$ and $L=60 \mathrm{~mm}$ )

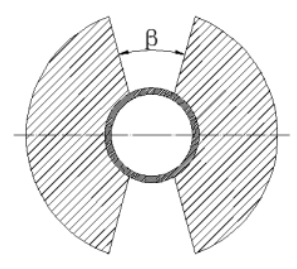

(a) Solid paddle

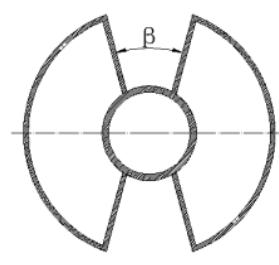

(b) Closed hollow paddle

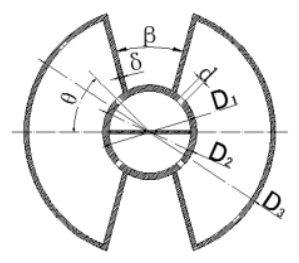

(c) Open hollow paddle
Figure 3. Scheme of paddle-shaft structures $\left(D_{l}=52 \mathrm{~mm}, D_{2}=60 \mathrm{~mm}, D_{3}=160 \mathrm{~mm}, \delta=3 \mathrm{~mm}\right)$

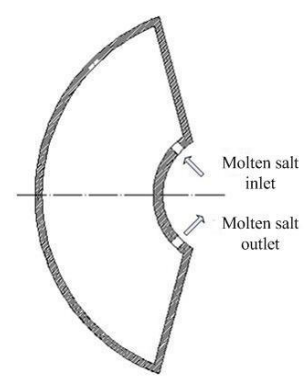

Figure 4. Computational domain of open hollow paddle
Besides paddle-shaft, rotary joint (Section 5) is another important component which connects hollow shafts and outside fluid loop (Fig. 5). For high temperature thermofluid (like molten salt) systems, thermal expansion-induced leakage is a critical fault mode. To solve this problem, reducing the temperature of the sealing packing is used as a design objective in order to improve the performance of rotary joints. Figure 5a is the original prototype of a rotary joint, and Fig. $5 \mathrm{~b}$ provides an alternative design with internal heat insulation layer between the hot molten salt and the sealing packing. More details can be found in Ref. [31].

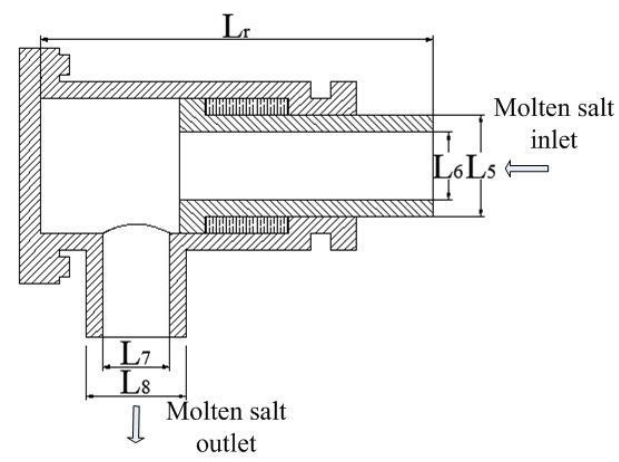

(a) Original structure

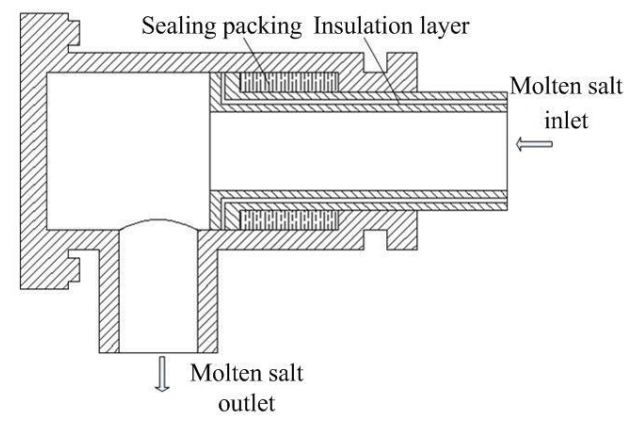

(b) Modified structure

Figure 5. Scheme of rotary joints

$$
\left(L_{5}=L_{8}=60 \mathrm{~mm}, L_{6}=L_{7}=40 \mathrm{~mm}, L_{r}=234 \mathrm{~mm}\right)
$$

For structures shown in Figs. 3 5, we simulated the flow and heat transfer performance by using a model for threedimensional conjugated heat transfer. The Reynolds-averaged model, with standard $k-\varepsilon$ turbulence model, is used to simulate molten salt turbulent forced flow process [32, 33]. For the closed hollow paddle-shaft structure shown in Fig. 3b, where air is trapped in the closed cavity, turbulent natural convection with standard $k-\varepsilon$ turbulent model is adopted to calculate the effect of air. Thermal radiation among inner surfaces of hollow paddles is included in the model [31].

In normal applications, the shafts of paddle heat exchangers rotate less than $50 \mathrm{rpm}$, and it has been confirmed that the effect of rotation rate on flow and heat transfer design is negligible [31]. The equation for heat conduction in solid is then given

$$
\nabla^{2} T=0
$$

where $\nabla^{2}=\partial^{2} / \partial x^{2}+\partial^{2} / \partial y^{2}+\partial^{2} / \partial z^{2}$.

The basic assumptions are: (1) steady flow for molten salt and air, (2) zero rotation rate, (3) no heat generation in solid, 
(4) constant properties for molten salt and solid, given in

Table 1 . The boundary conditions are summarized in Table 2.

Table 1. Properties of molten salt $\left(T=500^{\circ} \mathrm{C}\right)$ and stainless steel [31]

\begin{tabular}{|c|c|c|c|c|c|}
\hline Property & $\rho\left(\mathrm{kg} / \mathrm{m}^{3}\right)$ & $c_{p}(\mathrm{~J} /(\mathrm{kg} \mathrm{K}))$ & $\lambda(\mathrm{W} /(\mathrm{m} \mathrm{K}))$ & $\mu(\mathrm{kg} /(\mathrm{m} \mathrm{s}))$ & $\varepsilon$ \\
\hline Molten salt & 1715 & 1465 & 0.4665 & 0.000999 & \\
\hline Stainless steel & 7703 & 578.6 & 22.22 & & 0.2 \\
\hline Sealing packing & 2210 & 825 & 221 & & \\
\hline Insulation layer & 230 & 800 & 0.027 & & \\
\hline
\end{tabular}

Table 2. Boundary conditions

\begin{tabular}{|c|c|c|c|}
\hline Boundary condition & $\begin{array}{c}\text { Paddle-shaft structure } \\
\text { (Fig. 3) }\end{array}$ & $\begin{array}{c}\text { Open hollow paddle } \\
\text { (Fig. 4) }\end{array}$ & $\begin{array}{c}\text { Rotary joint } \\
\text { (Fig. 5) }\end{array}$ \\
\hline Fluid: inlet & $\begin{array}{c}\dot{m} \\
T_{i}=500^{\circ} \mathrm{C}\end{array}$ & $\begin{array}{c}\dot{m} \\
T_{i}=500^{\circ} \mathrm{C}\end{array}$ & $\begin{array}{c}\dot{m} \\
T_{i}=500^{\circ} \mathrm{C}\end{array}$ \\
\hline Fluid: outlet & $P=0.1 \mathrm{MPa}$ & $P=0.1 \mathrm{MPa}$ & $P=0.1 \mathrm{MPa}$ \\
\hline Solid: outside surfaces of paddles & $\begin{array}{c}T_{o}=200^{\circ} \mathrm{C} \\
h_{o}=500 \mathrm{~W} /\left(\mathrm{m}^{2} \mathrm{~K}\right)\end{array}$ & $T_{w}=400^{\circ} \mathrm{C}$ & $\begin{array}{c}T_{o r}=25^{\circ} \mathrm{C} \\
h_{o r}=5 \mathrm{~W} /\left(\mathrm{m}^{2} \mathrm{~K}\right)\end{array}$ \\
\hline Solid: end-wall surfaces of shaft & adiabatic & adiabatic & \\
\hline Solid: inside surface of paddles & & adiabatic & \\
\hline
\end{tabular}

The simulation results are summarized in dimensionless groups as follows.

$$
\begin{aligned}
& \operatorname{Re}=\frac{u D_{1}}{v} \\
& B e=\frac{\Delta P L^{2}}{\mu a} \\
& M=\frac{\dot{m}}{h_{o} \pi D_{2} L / c_{p}} \\
& \tilde{Q}=\frac{\dot{Q}}{h_{o} \pi D_{2} L\left(T_{i}-T_{o}\right)} \\
& \tilde{T}=\frac{T-T_{o}}{T_{i}-T_{o}}
\end{aligned}
$$

To solve the flow and heat temperature fields we used a finite-volume computational package ASNYS Fluent [34] with pressure-based solver SIMPLE algorithm. The mesh independence was checked before each simulation was performed. Less than $1 \%$ changes in pressure drops and heat transfer rates between successive mesh sizes are considered acceptable results. The number of grids used in the simulations varies from case to case.

\section{SOLID AND HOLLOW PADDLES}

Consider the evolving of paddles from solid structure to hollow structure in Fig. 3. Figure 6 compares the heat transfer rates for the three structures: solid paddle-shaft structures, closed hollow paddle-shaft structures and open hollow paddle- shaft structures. In the range $R e=26000 \sim 260000$, the heat transfer rate of the closed hollow paddle-shaft structure is 3\% 10\% higher than that of the solid paddle-shaft structure mainly due to the air natural convection in the closed cavities in paddles, but the open hollow paddle-shaft structure transfers approximate 2.5 times heat of the solid paddle-shaft or closed hollow paddle-shaft structures. The performance superiority of open hollow paddle-shaft structure documented here demonstrates the design optimization (or constructal evolving) direction, from conduction to natural convection (of air) to forced convection (of molten salt).

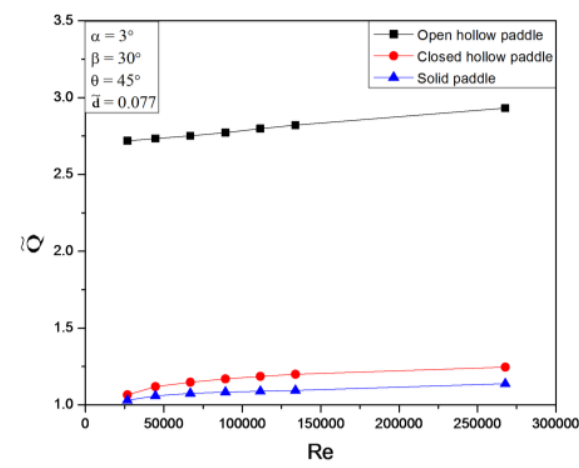

Figure 6. Heat transfer rates of three paddle structures

$$
\left(\tilde{d}=d / D_{1}\right)
$$

One example of the temperature field of solid is shown in Fig. 7. The results are for the outside surfaces of the entire paddle-shaft structures. The outside surface temperature of open hollow paddles is higher than that of solid paddles and closed hollow paddles. For open hollow paddles, in the corner regions far from the open holes, the temperature (equivalent to the local heat transfer rate) is lower than that in the center region (also cf. Fig. 9). 

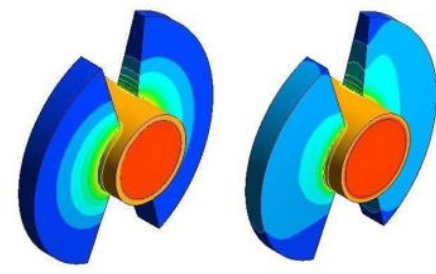

(a) Solid paddle

(b) Closed hollow paddle

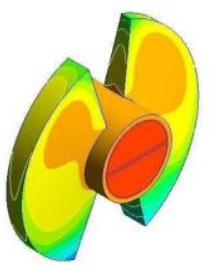

(c) Open hollow paddle
Figure 7. Temperature field of outside surfaces of three paddle structures $(R e=89270)$

Figure 6 also shows the effect of $R e$ (or dimensionless flow rate) which is based on the inlet size of the hollow shaft [Eq. (2)]. Assume the flow is uniformly distributed into the $N$-pair open hollow paddles. The mass flow rate in one element (Fig. 3 ) is only $1 / N$ of the total flow rate. When $R e$ increases from 26000 to 260000 , the heat transfer rate is increased $10.5 \%$ for the solid paddle-shaft structure, $16.9 \%$ for the closed hollow paddle-structure and $7.9 \%$ for the open hollow paddlestructure respectively. Note that when $h_{o}$ varies, the quantitative effect of $R e$ on the heat transfer rate is different. For solid paddles and closed hollow paddles, as fluid does not flow through the inner space of hollow paddles, $B e_{S P}<<$ $B e_{O H P}$ and $B e_{C H P}<<B e_{O H P}$. In Ref. [31], it gives the order of magnitude: $B e_{O H P} \sim 100 B e_{S P}$ or $100 B e_{C H P}$. It means that much more power is to be consumed to drive molten salt flow for open hollow paddle-shaft structures than for solid paddleshaft and closed hollow paddle-shaft structures. This is the price that open hollow paddles have to pay for improving the heat transfer performance.

\section{OPEN HOLLOW PADDLES}

We further evolve (or optimize) the structure of open hollow paddles. First we discuss the effect of the position angle $\theta$ of the open holes. For specified mass flow rates, Fig. 8 shows the peak pressure drop and peak heat transfer rate relative to the position angle $\theta$. For two flow rates in Figs. 8 and 9 , the peak pressure drop and peak heat transfer rate emerges at nearly the same $\theta \approx 42.5^{\circ}$. When $M=10.36$ and 103.6, $B e_{\max }=1.216 \times 10^{11}$ and $1.244 \times 10^{13}, \tilde{Q}=1.828$ and 4.739 respectively. When $\theta \approx 45^{\circ}$, the four holes for one pair of paddles is uniformly distributed circumferentially, that is the normal option found in practice.

Figure 9 shows one example of the flow field and the temperature field of molten salt. The results are for the symmetrical cross-section of the open hollow paddle. We see that eddy zones exist and the flow does not bath the entire space uniformly. The temperature distribution (or gradient) is not ideal. The observation reveals that there is room for further improvement in design.

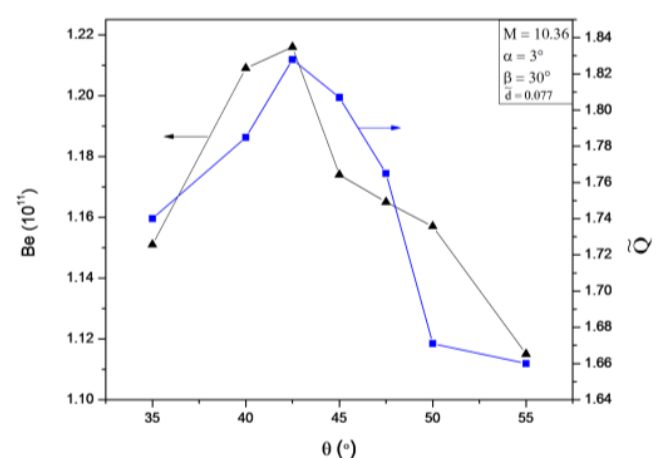

(a)

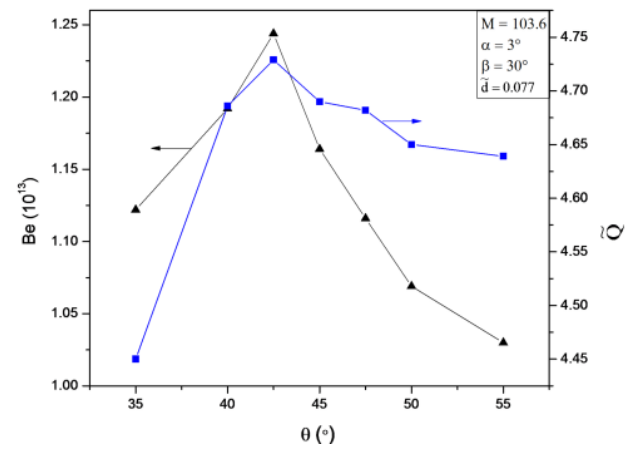

(b)

Figure 8. The effects of the position angle $\theta$

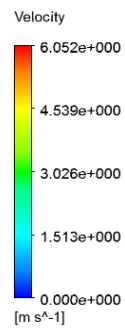

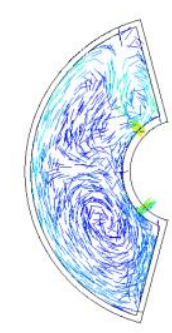

a) Flow field
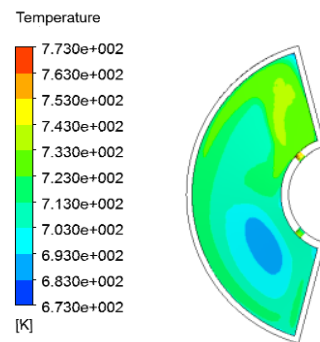

(b) Temperature field
Figure 9. Flow field and temperature field of open hollow paddle structure

$$
\left(\alpha=3^{\circ}, \beta=30^{\circ}, \theta=45^{\circ}, \tilde{d}=0.077, M=10.36\right)
$$

Figure 10 shows the effects of the diameter of open holes $\tilde{d}$ and the dimensionless pressure drop Be. When $\tilde{d}$ changes from $0.077(d=4 \mathrm{~mm})$ to $0.115(d=6 \mathrm{~mm})$, the mass flow rate and heat transfer rate increase significantly. For instance, when $B e=2.13 \times 10^{11}, M$ and $\tilde{Q}$ increase $100 \%$ and $32.5 \%$ respectively. Consider that molten salt will solidify when its temperature is lower than its melting temperature $\left(142^{\circ} \mathrm{C}\right.$ for Hitec salt). To start the paddle heat exchanger smoothly or avoid possible blockage, larger $\tilde{d}$ is to some extent necessary with the penalty of reduced mechanical strength. 


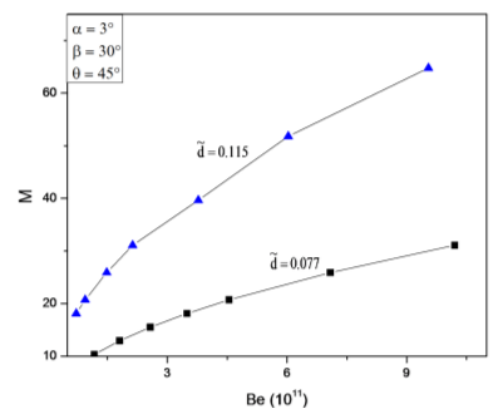

(a)

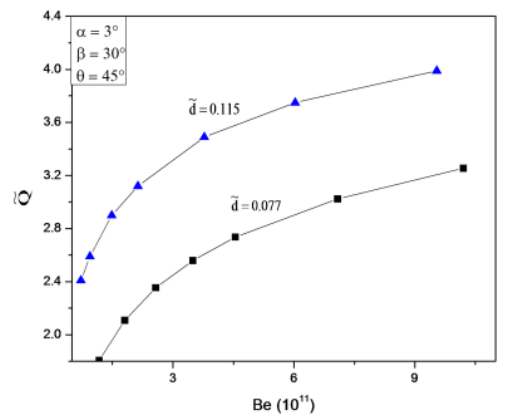

(b)

Figure 10. The effects of open hole size $d$ and pressure drop

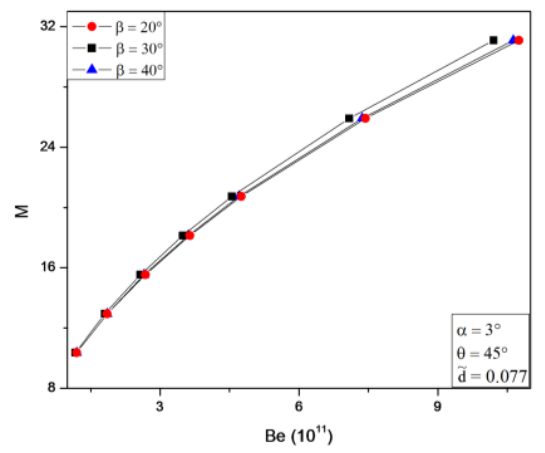

(a)

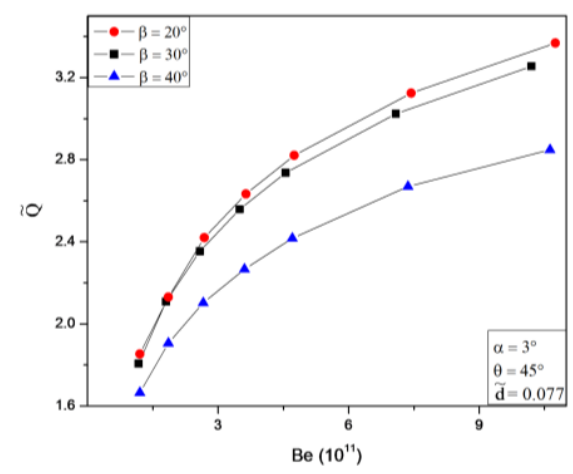

(b)

Figure 11. The effect of the non-finned angle $\beta$

Figure 11a shows the effect of the non-finned angle $\beta$ on the mass flow rate and heat transfer rate. When $B e$ is small, the effect of $B e$ on $M$ is negligible. When $B e$ is larger, the structure with $\beta=30^{\circ}$ provides higher flow rate than that with $\beta=20^{\circ}$ or $40^{\circ}$. There is no significant gap between $\beta=20^{\circ}$ or $40^{\circ}$ in the range $B e=1.1 \times 10^{11} \sim 10 \times 10^{11}$. This observation tells that the change of $M$ with $\beta$ is not monotonous. The effect of $\beta$ on $\tilde{Q}$ is different from that on $M$ (Fig.11b). $\tilde{Q}$ increases as $\beta$ decreases, which corresponds to larger heat transfer area. When $B e$ is small, the effect of $\beta$ on $\tilde{Q}$ is weak especially for $\beta=20^{\circ}$ and $30^{\circ}$. It should be noted that $\beta$ also influences the flow characteristics of shell-side materials. The design on both two sides should be taken into account to get a proper $\beta$.

\section{ROTARY JOINTS}

To decrease the thermal expansion (or temperature) in the sealing packing domain, we inserted heat insulation layer with thickness $t$ in the inner tube wall (Fig.5b). This structure weakens the heat flow from the hot molten salt to the sealing packing domain and more heat is dissipated through paths where there is no heat insulation. Meanwhile, if external cooling at the outside surface is performed, the average temperature in the sealing packing domain can be further reduced. Figure 12 documents the average temperature $\tilde{T}$ and the heat loss $\tilde{Q}$ for the structures before and after modification. For instance, when $B e=2.77 \times 10^{10}$, for the original structure and the modified structure with $t=2 \mathrm{~mm}$ and $h_{o r}=40 \mathrm{~W} /\left(\mathrm{m}^{2} \mathrm{~K}\right)$, the dimensionless average temperature in the sealing packing domain is 0.97 (equivalent to $490^{\circ} \mathrm{C}$ ) and 0.52 (equivalent to $356^{\circ} \mathrm{C}$ ) respectively, and the dimensionless heat loss increases from 0.361 to 1.136 .

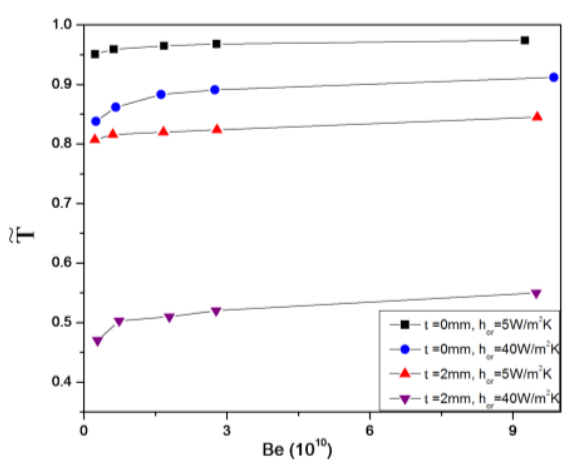

(a)

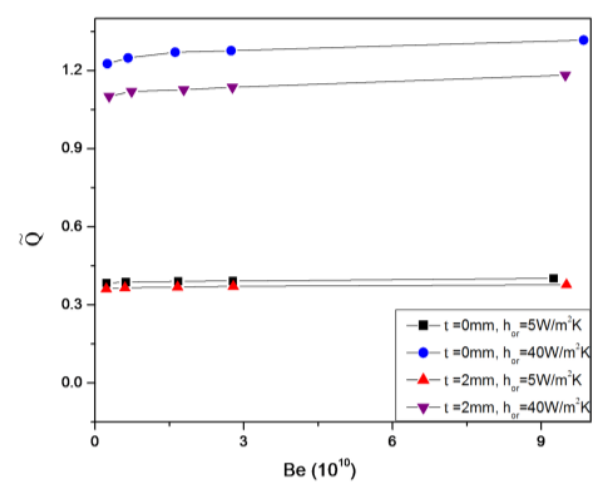

(b)

Figure 12. The average temperature of sealing packing domain 
Examples of the temperature fields are shown in Fig.13. The results are for the symmetrical cross-sections. When internal heat insulation is adopted, the average temperature in the sealing packing domain decreases significantly. This means that better sealing performance may be achieved.

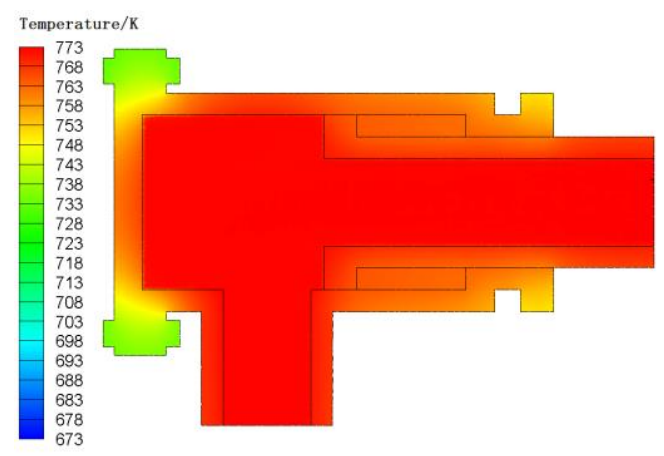

(a) Original structure $\left(t=0 \mathrm{~mm}, h_{o r}=5 \mathrm{~W} / \mathrm{m}^{2} \mathrm{~K}\right)$

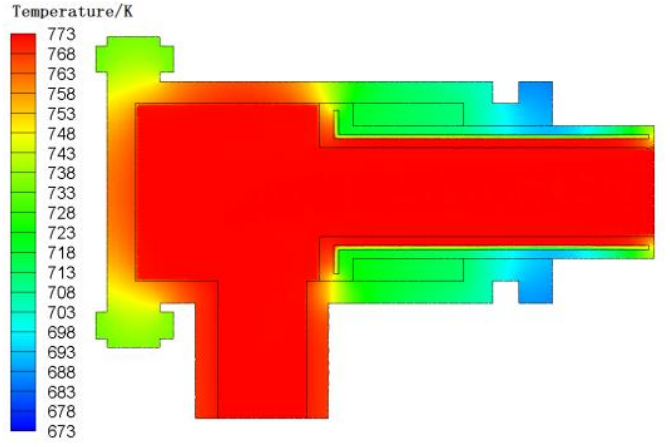

(b) Modified structure $\left(t=2 \mathrm{~mm}, h_{o r}=5 \mathrm{~W} / \mathrm{m}^{2} \mathrm{~K}\right)$

Figure 13. The temperature fields of rotary joints

\section{CONCLUSIONS}

In this paper we used constructal design method and threedimensional numerical simulations to document molten salt flow and heat transfer performance in paddle heat exchangers. Three paddle-shaft structures were compared. The results show that there exists an evolving direction (from conduction to air natural convection to molten salt forced convection) aiming to improve the heat transfer performance of paddleshaft structures. If the flow rate at the inlet of the hollow shafts is specified, open hollow paddle-shaft structure provides greater heat transfer capability than solid paddleshaft and closed hollow paddle-shaft structures.

For open hollow paddles, there is an open hole position at which pressure drop and heat transfer rate approach maximum simultaneously for specified flow rates. The flow rate and heat transfer rate increase significantly as the hole diameter increases. When the non-finned angle decreases, the heat transfer rate increases whereas the change of the flow rate is not monotonous.

The comparison of original and modified rotary joints shows that internal heat insulation combined with external cooling drops the average temperature in the sealing packing domain efficiently which helps improve the sealing performance under high molten salt temperature conditions. When external cooling is used, the heat loss increases too.
The present work provides more insight in molten salt flow and heat transfer in paddle heat exchangers. It shows that heat transfer optimization of molten salt in paddle heat exchangers is available and trade-off (between heat transfer and pressure drop or between temperature control and heat loss) is necessary. In practice, more factors like mechanical strength and manufacture cost should be taken into account

\section{NOMENCLATURE}

\begin{tabular}{|c|c|}
\hline$a$ & thermal diffusivity \\
\hline$B e$ & dimensionless pressure drop (Bejan number) \\
\hline$c_{p}$ & $\begin{array}{l}\text { specific heat at } \\
\text { constant pressure }\end{array}$ \\
\hline$d$ & diameter of open holes \\
\hline$\tilde{d}$ & $\begin{array}{l}\text { dimensionless diameter } \\
\text { of open holes }\end{array}$ \\
\hline$D_{1}, D_{2}, D_{3}$ & Fig.3 \\
\hline$h_{o}$ & $\begin{array}{l}\text { convective heat transfer coefficient for outside } \\
\text { surfaces }\end{array}$ \\
\hline$h_{o r}$ & $\begin{array}{l}\text { convective heat-transfer coefficient for outside } \\
\text { surfaces of rotary joints }\end{array}$ \\
\hline$H$ & Fig.2 \\
\hline$L, L_{1} \sim L_{4}$ & Fig. 2 \\
\hline$L_{r}, L_{5} \sim L_{8}$ & Fig.5 \\
\hline$\dot{m}$ & mass flow rate \\
\hline$M$ & $\begin{array}{l}\text { dimensionless mass } \\
\text { flow rate }\end{array}$ \\
\hline$N$ & $\begin{array}{l}\text { the number of pairs of } \\
\text { paddles }\end{array}$ \\
\hline$P$ & pressure \\
\hline$\Delta P$ & pressure drop \\
\hline$\dot{Q}$ & heat transfer rate \\
\hline$\widetilde{Q}$ & $\begin{array}{l}\text { dimensionless heat } \\
\text { transfer rate or heat } \\
\text { loss }\end{array}$ \\
\hline $\operatorname{Re}$ & Reynolds number \\
\hline$t$ & $\begin{array}{l}\text { thickness of insulation } \\
\text { layer }\end{array}$ \\
\hline$T$ & $\begin{array}{l}\text { temperature } \\
\text { dimensionless }\end{array}$ \\
\hline$\tilde{T}$ & $\begin{array}{l}\text { temperature or average } \\
\text { temperature }\end{array}$ \\
\hline$T_{i}$ & inlet temperature \\
\hline$T_{o}$ & $\begin{array}{l}\text { temperature of shell- } \\
\text { side materials } \\
\text { outside ambient }\end{array}$ \\
\hline$T_{o r}$ & $\begin{array}{l}\text { temperature of rotary } \\
\text { joint }\end{array}$ \\
\hline$T_{w}$ & $\begin{array}{l}\text { temperature of } \\
\text { outside walls }\end{array}$ \\
\hline$u$ & $\begin{array}{l}\text { velocity along axial } \\
\text { direction }\end{array}$ \\
\hline$x, y, z$ & coordinates \\
\hline
\end{tabular}

\section{Greek symbols}

$\alpha \quad$ inclined angle of paddles 
$\beta \quad$ non-finned angle

$\delta \quad$ thickness of hollow paddles

$\varepsilon \quad$ emissivity

$\theta \quad$ position angle of open holes

$\lambda \quad$ thermal conductivity

$\mu \quad$ dynamic viscosity

$v \quad$ kinematic viscosity

$\rho \quad$ density

\section{Subscripts}

$\begin{array}{ll}\text { CHP } & \text { closed hollow paddle } \\ \text { max } & \text { maximum } \\ \text { OHP } & \text { open hollow paddle } \\ \text { SP } & \text { solid paddle }\end{array}$

\section{ACKNOWLEDGMENT}

This work was supported by Lianyungang City Science and Technology Bureau and Nanjing University of Science and Technology, China.

\section{REFERENCES}

1. Pan Y., Wang X., Liu X., Modern Drying Technology (in Chinese), Chemical Industry Press, 2006.

2. Arlabosse P., Chavez S., Lecomte D., "Method for thermal design of paddle dryers: application to municipal sewage sludge," Drying Technology, 22, 2375-2393, 2004. DOI: 10.1081/DRT-200040041.

3. Arlabosse P., "Heat and mass transfer during fry-drying of sewage sludge," Chermical Engineering Transactions, 7, 701-706, 2005. DOI: 10.1080/07373930600733085.

4. Arlabosse P., Chavez S., Precot C., "Drying of municipal sewage sludge: From a laboratory scale batch indirect dryer to the paddle dryer," Brazilian Journal Chemical Engineering, 22, 227-232, 2005. DOI: 10.1590/S0104-66322005000200009.

5. Arlabosse P., Chitu T., "Identification of the limiting mechanism in contact drying of agitated sewage sludge," Drying Technology, 25, 557-567, 2007. DOI: $10.1080 / 07373930701226955$.

6. Deng W., Yan J., Li X. et al., "Measurement and simulation of the contact drying of sewage sludge in a Nara-type paddle dryer based on batch experiments," Chemical Engineering Science, 64, 5117-5124, 2009. DOI: $10.1016 /$ j.ces.2009.08.015.

7. Zhang H., Liu X., Zhu S. et al., "Sewage sludge flow and drying characteristics in paddle dryers," Defect and Diffusion Forum, 334-335, 365-368, 2013.

8. Zhang H., Liu X., Zhu S. et al., "Brown coal drying device and method based on size grading," China Patent, 201210403540.5 (in Chinese), 2014.

9. Wang W., Zhang H. and Liu X., "Research and application prospects of coal slime in paddle dryers (in Chinese)," Industrial Boiler, 149, 34-36, 2015.

10. Hoffman H., Lones J., "Fused salt heat transfer, Part II : Forced convection heat transfer in circular tubes containing NaF-KF-LiF eutectic," Report No.ORNL1777, Oak Ridge National Laboratory, 1955.

11. Hoffman H., Cohen S., "Fused salt heat transfer, Part III: Forced convection heat transfer in circular tubes containing the salt mixture $\mathrm{NaNO}_{2}-\mathrm{KNO}_{3}-\mathrm{NaNO}_{3}$," Report No. ORNL-1777, Oak Ridge National Laboratory, 1960.

12. Cooke J., Cox B., "Forced-convection heat transfer measurements with a molten fluoride salt mixture flowing in a smooth tube," Report No.ORNL-TM-4079, Oak Ridge National Laboratory, 1973.

13. Wu Y., Chen C., Liu B., "Investigation on forced convective in heat transfer of molten salts in circular tubes," International Communications in Heat and Mass Transfer, 39, 1150-1155, 2012. DOI: 10.1016/j.icheatmasstransfer.2012.09.002.

14. Feng Y., Lin K., Chi C., "CFD investigating thermalhydraulic characteristics of FLiNaK salt as a heat exchange fluid," Applied Thermal Engineering, 37, 235 240, 2012. DOI: 10.1016/j.applthermaleng.2011.11.021.

15. Srivastava A., Vaidya A., Maheshwari N., "Heat transfer and pressure drop characteristics of molten fluoride salt in circular pipe," Applied Thermal Engineering, 61, 198-205, 2013.2 DOI: 10.1016/j.applthermaleng.2013.07.051.

16. Lu J., Shen X., Ding J., "Convective heat transfer of high temperature molten salt in transversely grooves tube," Applied Thermal Engineering, 61, 157-162, 2013. DOI: $10.1016 /$ j.applthermaleng.2013.07.037.

17. Lu J., He S., Ding J., "Convective heat transfer of high temperature molten salt in vertical annular duct with cooled wall," Applied Thermal Engineering, 85, 122127, 2014. DOI: $10.1016 /$ j.applthermaleng.2014.05.098.

18. Reilly H., Kolb G., "An evaluation of molten-salt power towers including results of the solar two project," Report of Sandia National Laboratories, 2001.

19. Yang M., Yang X., Yang X., "Heat transfer enhancement and performance of the molten salt receiver of a solar power tower," Applied Energy, 87, 2808-2811, 2010. DOI: 10.1016/j.apenergy.2009.04.042.

20. Zhang Q., Li X., Chang C., "An experimental study: thermal performance of molten salt cavity receivers," Applied Thermal Engineering, 50, 334-341, 2013. DOI: 10.1016/j.applthermaleng.2012.07.028.

21. Bejan A., Lorente S., "Design with Constructal Theory," John Wiley \& Sons, 2008. DOI: 10.1002/9780470432709.

22. Bejan A., Lorente S., "Constructal multi-scale and multiobjective structures," International Journal of Energy, 29, 689-710, 2005. DOI: 10.1002/er.1100.

23. Bejan A., Lorente S., "Constructal tree-shaped flow structures," Applied Thermal Engineering, 27, 775-761, 2007. DOI: $10.1016 / \mathrm{j}$. applthermaleng.2006.10.008.

24. Bejan A., Lorente S., "Vascularized smart materials: designed porous media for self-healing and selfcooling," Journal of Porous Media, 12, 1-18, 2009.

25. Rocha L., Lorente S., Bejan A. et al., "Constructal design of underground heat sources or sinks for the annual cycle," International Journal of Heat and Mass Transfer, 55, 25-26, 2012. DOI: 10.1016/j.ijheatmasstransfer.2012.08.010.

26. Bejan A., Lorente S., Kim Y. et al., "Power from a hot gas stream with superheater and reheater in parallel," International Journal of Heat and Mass Transfer, 73, 29-32, 2014.

DOI: 10.1016/j.ijheatmasstransfer.2014.01.049.

27. Bejan A., Lorente S., Kang D., "Constructal design of thermoelectric power packages," International Journal 
of Heat and Mass Transfer, 79, 291-299, 2014. DOI: 10.1016/j.ijheatmasstransfer.2014.08.008.

28. Cetkin E., Lorente S., Bejan A., "Vascularization for cooling and reduced thermal stresses," International Journal of Heat and Mass Transfer, 80, 858-864, 2015. DOI: 10.1016/j.ijheatmasstransfer.2014.09.027.

29. Lorente S., Bejan A., Niu J., "Constructal design of latent thermal energy storage with vertical spiral heaters," International Journal of Heat and Mass Transfer, 81, 283-288, 2015. DOI: 10.1016/j.ijheatmasstransfer .2014.09.077.

30. Rodrigues M., Brum R., Vaz J. et al., "Numerical investigation about the improvement of the thermal potential of an earth-air heat exchangers (EAHE) employing the constructal design method," Renewable Energy, 80, 538-551, 2015. DOI: 10.1016/j.renene.2015.02.041.

31. Du J., Research on high temperature molten salt in paddle heat exchangers (in Chinese), Thesis of Nanjing University of Science and Technology, 2015.

$32 \mathrm{Wu}$ W., Fluid Mechanics (in Chinese), Peking University Press, 1982.

33. Anderson J., Computational Fluid Dynamics, China Machine Press, 2007.

34. ANSYS Fluent, version 14.0, User's Manual, Fluent Inc. 